Int. J. Electrochem. Sci., 11 (2016) $9110-9122$

\title{
Effect of Process Parameters for Oxygen Plasma Activation of Carbon Nanofibers on the Characteristics of Deposited Platinum Nanoparticles as Electrocatalyst in Proton Exchange Membrane Fuel Cells
}

\author{
Ulrich Rost ${ }^{1,2}$, Roxana Muntean ${ }^{1,2, ~ *, ~ G a b r i e l a ~ M a ̆ r g i n e a n ~}{ }^{1}$, César Merino ${ }^{3}$, Roberto Díez ${ }^{3}$, \\ Nicolae Vaszilcsin ${ }^{2}$, Michael Brodmann ${ }^{1}$ \\ ${ }^{1}$ Westphalian Energy Institute, Westphalian University of Applied Sciences, 45897, Gelsenkirchen, \\ Germany \\ ${ }^{2}$ Faculty of Industrial Chemistry and Environmental Engineering, Politehnica University Timişoara, \\ 300006 Piața Victoriei 2, Timișoara, Romania \\ ${ }^{3}$ Grupo Antolin Ingeniería, SA, Ctra. Madrid - Irún, E09007 Burgos, Spain \\ *E-mail : roxana.muntean@upt.ro
}

doi: $10.20964 / 2016.11 .55$

Received: 22 July 2016 / Accepted: 29 August 2016 / Published: 10 October 2016

In the polymer electrolyte membrane fuel cells (PEMFC) state of the art, rare and expensive platinum group metals (PGM) or PGM alloys are used as catalyst material. Reduction of PGMs in PEMFC electrodes is strongly required to reach cost targets for this technology. An optimal catalyst utilization is achieved in case of nano-structured particles supported on carbon material with a large specific surface area. In this study, graphitic material, in form of carbon nanofibers (CNF), is decorated with $\mathrm{Pt}$ particles, serving as catalyst material for PEMFC electrodes with low Pt loading. As a novelty, the effect of oxygen plasma treatment of CNFs previously to platinum particle deposition has been studied. Electrodes are investigated in respect of the optimal morphology, microstructure as well as electrochemical properties. Therefore, samples are characterized by means of scanning electron microscopy combined with energy dispersive X-ray analysis, transmission electron microscopy, thermogravimetry, X-ray diffraction as well as X-ray fluorescence analysis. In order to determine the electrochemical active surface area of catalyst particles, cyclic voltammetry has been performed in 0.5 M sulphuric acid. Selected samples have been investigated in a PEMFC test bench according to their polarization behavior.

Keywords: PEM fuel cell electrocatalysts, Carbon nanofibers, Oxygen plasma activation, Pulsed electroplating.

\section{FULL TEXT}


(C) 2016 The Authors. Published by ESG (www.electrochemsci.org). This article is an open access article distributed under the terms and conditions of the Creative Commons Attribution license (http://creativecommons.org/licenses/by/4.0/). 